\title{
Retinal Vascular Disorder
}

National Cancer Institute

\section{Source}

National Cancer Institute. Retinal Vascular Disorder. NCI Thesaurus. Code C35170.

Retinal damage resulting from diminished blood flow/oxygenation due to abnormalities of the retinal vessels. Causes include hypertension, diabetes, thrombosis, embolism, and hemorrhage. 